\title{
Accumulation of Radioactivity in Rat Brain and Peripheral Tissues Including Salivary Gland after Intravenous Administration of ${ }^{14} \mathrm{C}$-D-aspartic Acid
}

\author{
By Kazuhiro ImaI, $\left.{ }^{*},+\right)$ Takeshi Fukushima, ${ }^{*)}$ Tomofumi Santa, $\left.{ }^{*}\right)$ Hiroshi Homma, ${ }^{*)}$ Juko Sugihara, $\left.{ }^{* *}\right)$ \\ Hirohiko KodAMA, ${ }^{* *)}$ and Masayoshi YoshIKAWA**) \\ (Communicated by Masanori OTsukA, M. J. A., March 12, 1997)
}

\begin{abstract}
After the intravenous administration of ${ }^{14} \mathrm{C}$-D-aspartic acid (Asp) into Sprague-Dawley rats (male, 7-week-old), the distribution and elimination of radioactivity was investigated by the whole body autoradiography. High radioactivities were detected in pineal gland, pituitary gland and salivary gland at $30 \mathrm{~min}$ after administration. The other tissues detected were liver, lung, adrenal gland, pancreas and spleen where DAsp was reported to occur naturally. After $24 \mathrm{hr}$, the radioactivities were still detected at high levels in the pineal, pituitary and salivary glands. The data suggested the natural occurrence of D-Asp in salivary gland. After careful examination utilizing fluorescent derivatization and chiral separation by high-performance liquid chromatography, the presence of D-Asp was, for the first time, demonstrated in salivary gland in situ, the concentration of which was $7.85 \pm 1.0 \mathrm{nmol} / \mathrm{g}$. The administration of ${ }^{14} \mathrm{C}$-L-Asp was also carried out. The data suggested that D-Asp in the circulating blood is one of the sources of the tissue D-Asp.
\end{abstract}

Key words : ${ }^{14} \mathrm{C}$-D-aspartic acid; rat tissue; accumulation; salivary gland; autoradiography; chiral separation.

Introduction. Although amino acids in mammalian tissues and body fluids have been considered to consist solely of L-enantiomers, the recent findings that several Damino acids (D-Ala, -Asp, -Glu, -Pro, -Ser, -Leu and -Glu) are present in the mammalian brain and the peripheral tissues suggested that they may play some important biological roles in mammals. ${ }^{1)}$ Especially, D-Ser has been suggested to play a role as an intrinsic ligand for the glycine sensitive N-methyl-D-aspartate (NMDA) receptor. ${ }^{2,3)}$ On the other hand, although D-Asp emerged in the transient and distinct period of life of human and other mammalian brain regions (retina, ${ }^{4)}$ cerebrum, ${ }^{5)-7)}$ pituitary gland ${ }^{7)-9)}$ and pineal gland ${ }^{9), 10)}$ ) and the peripheral tissues (adrenal, testis and kidney), ${ }^{5), 8)}$ its biological role has not yet been clarified, except that D'Aniello et al. suggested its involvement in the synthesis of testosterone in the rat testis. $^{11)}$

As to the occurrence in mammals, D-Asp has been

*) Faculty of Pharmaceutical Sciences, University of Tokyo, 7-3-1 Hongo, Bunkyo-ku, Tokyo 113, Japan.

**) Pharmaceutical Development Research Laboratory, Tanabe Seiyaku Co. Ltd., 2-2-50 Kawagishi, Toda-shi, Saitama 335, Japan.

t) Correspondence to: K. Imai. reported to be present also in the blood. ${ }^{7), 9)}$ Although the source of D-Asp in the circulating blood is still ambiguous, much attention has been paid to whether it has some relation with D-Asp in the tissues so far observed. Thus, in this paper, we adopted ${ }^{14} \mathrm{C}$-labelled D-Asp for tracing the fate of D-Asp in blood by intravenous administration to rats, whereas the administration of ${ }^{14} \mathrm{C}$-L-Asp was also done for comparison. It was demonstrated that the radioactivities distributed in the selected brain regions such as the pineal and pituitary glands in addition to the peripheral tissues including salivary gland. Based on the findings, we quantified D-Asp in salivary gland following fluorescent derivatization, chiral separation and detection by high-performance liquid chromatography (HPLC), and demonstrated the occurrence of D-Asp in situ in the tissue. A discussion is made on the source of the tissue $\mathrm{D}$ Asp in rats.

Materials and method. Chemicals. ${ }^{14} \mathrm{C}-\mathrm{D}$-Asp and ${ }^{14} \mathrm{C}$-L-Asp, labelled at the carbon of $\beta$-carboxyl group were purchased from American Radiolabelled Chemicals Inc. (MO, USA). Both of the specific activities were 2.00-2.04 GBq/mmol. Their radiochemical purities checked by paper chromatography were greater than $99 \%$, 
whereas the chemical purities were 89.3 and $96.8 \%$ for DAsp and L-Asp, respectively. Carboxymethylcellulose (CMC) was of special grade from Katayama Chemical Co., Ltd. (Osaka, Japan). 4-Fluoro-7-nitro-2, 1, 3-benzoxadiazole $(\mathrm{NBD}-\mathrm{F})^{12), 13)}$ was purchased from Tokyo Kasei Kogyo Co., Ltd. (Tokyo, Japan). Sumichiral OA-2500 (S) and $-2500(\mathrm{R})$ were kindly donated by Sumika Analytical Center, Co., Ltd. (Osaka, Japan). Methanol (MeOH) and acetonitrile $\left(\mathrm{CH}_{3} \mathrm{CN}\right)$ were of HPLC grade from Kanto Chemical Co., Ltd. (Tokyo, Japan). The other reagents used were of analytical grade.

Administration to rats. The male Sprague-Dawley rats (7-week-old, 210-220 g, Charles River Japan Inc.) were allowed to feed (CE-2, Clea Japan Inc., Tokyo, Japan) and drink ad libitum in an enviromentally controlled room with 12-hour light/dark cycle. The $0.1 \mathrm{~N}$ hydrochloric acid solution of ${ }^{14} \mathrm{C}$-D-Asp or ${ }^{14} \mathrm{C}$-L-Asp was neutralized with $1 \mathrm{~N}$ sodium hydroxide and diluted to $0.4 \mu \mathrm{mol} / \mathrm{ml}$ with a physiological saline. The intravenous administration was made into the right femoral vein $(170-174 \mathrm{KBq} / 85-86$ $\mathrm{nmol} / \mathrm{rat}$ ) under anesthesia with diethyl ether.

Whole body autoradiography. At 0.5, 3 and 24 hours after administration, the rats were anesthetized with diethyl ether and immediately frozen by immersion into a mixture of dry ice-acetone $\left(-70^{\circ} \mathrm{C}\right)$ and stored at $-20^{\circ} \mathrm{C}$ for 2 days. Then they were embedded in $3 \% \mathrm{CMC}$ in $\mathrm{H}_{2} \mathrm{O}$ and placed on a microtome stage. The sagittal sections of $40 \mu \mathrm{m}$ in thickness were prepared by an autocryotome (Cryomacrocut, Leica Instruments $\mathrm{GmbH}$, Nussloch, Germany) with an adhesive tape (Sumitomo 3M Co. Ltd., Tokyo, Japan). The sections were freeze-dried, wrapt in Milar film (Nakagawa, Tokyo, Japan), and in contact with the imaging plates made from the photo-stimulable phosphor, BaFBr:Eu ${ }^{2+}$ (Fuji Photo Co., Ltd., Tokyo, Japan). They were exposed for 3 days at $4^{\circ} \mathrm{C}$ in a lead case without lighting. The imaging plates were then analyzed using a Bio-imaging analyzer (Bas-2000, Fuji Photo Film Co., Ltd., Tokyo, Japan). The autoradiograms of the whole body thus obtained were quantitated with the calibration curve of the standard of ${ }^{14} \mathrm{C}$ using the Bioimaging analyzer.

Identification and quantification of D-Asp in salivary gland in situ. The identification and determination of $\mathrm{D}$ Asp in salivary gland was carried out in the same manner as described in the previous reports. ${ }^{10)}$ The male Sprague-Dawley rats (7-week-old) were anesthetized with diethyl ether and sacrificed by withdrawing blood from the abdominal aorta. Then, each salivary gland was immediately removed, and homogenized in 9 volumes of methanol under the ice cooling after weighing and mincing. After centrifugation at 3,000 $\mathrm{g}$ for $5 \mathrm{~min}$, the supernatant was evaporated to dryness by a centrifugal evaporator, SPE200 (Shimadzu, Tokyo, Japan). The residue was dissolved in $20 \mu \mathrm{L}$ of $0.2 \mathrm{M}$ borate buffer $(\mathrm{pH}$ 8.0) with the addition of $30 \mu \mathrm{L}$ of $50 \mathrm{mM} \mathrm{NBD}-\mathrm{F}$ in $\mathrm{CH}_{3} \mathrm{CN}$, heated at $60^{\circ} \mathrm{C}$ for 5 min to obtain NBD-amino acids. Then, $950 \mu \mathrm{L}$ of $1.0 \%$ $\mathrm{AcOH}$ in $\mathrm{MeOH}$ was added to the solution to stop the reaction, and finally diluted 10 times with the mobile phase prior to injection to the following HPLC.

The HPLC system used was consisted of a BIP-I HPLC pump, an FP-920 Spectrofluorescence detector (Jasco, Tokyo, Japan) and a D-7500 Chromato-Integrator (Hitachi, Tokyo, Japan). The enantiomeric separation of NBD-labelled D, L-Asp was performed with the Pirkle type stationary phase (Sumichiral OA-2500 (S) or $(\mathrm{R})),{ }^{14), 15)}$ using the mobile phase of $8.0 \mathrm{mM}$ citric acid in $\mathrm{MeOH}$ for Sumichiral OA-2500 (S), and $10 \% \mathrm{CH}_{3} \mathrm{CN}$ in 8.0 $\mathrm{mM}$ citric acid in $\mathrm{MeOH}$ for Sumichiral OA-2500 (R). The fluorescence detection was made at $530 \mathrm{~nm}$ with $470 \mathrm{~nm}$ as an excitation wavelength. The flow rate was at $1.0 \mathrm{ml} / \mathrm{min}$, and the column temperature was ambient. The quantitation of NBD-D-Asp in salivary gland was made by the calibration curve of the standard of D, L-Asp versus fluorescence peak area.

Results. The whole body autoradiograms at $0.5 \mathrm{hr}$, $3 \mathrm{hr}$ and $24 \mathrm{hr}$ after the intravenous administration of ${ }^{14} \mathrm{C}$ D-Asp into rats (7-week-old) are shown in Fig. 1. It clearly shows that at $0.5 \mathrm{hr}$ after the injection, the radioactivities were detected in the pineal gland, pituitary gland, salivary gland, liver, lung, adrenal gland, pancreas, spleen and testis (Figs. 1a and a'). The quantification data of radioactivity in the tissues (Table I) show that the highest radioactivity was observed in the pineal gland, followed by the salivary and pituitary glands $(289,011,177,119$ and $77,775 \mathrm{dpm} / \mathrm{g}$, respectively). High values were also observed in the lung, liver, pancreas and spleen, but low radioactivities were detected in the adrenal gland and testis.

The rapid elimination of the radioactivity was observed within $0.5 \mathrm{hr}$ to $3 \mathrm{hr}$ in most of the tissues, whereas a slow elimination was observed in blood indicating the circulation of the increased amounts of metabolites of ${ }^{14} \mathrm{C}$-D-Asp. In contrast, the high radioactivities still remained in the tissues of pineal gland, pituitary gland and salivary gland (Figs. 1b and b', Table I).

The radioactivity was still remained high at $24 \mathrm{hr}$ in the pineal gland (Figs. 1c and c', Table I), where the highest concentration of D-Asp was observed in situ (6 to 10-week old rat). ${ }^{9)}$ The radioactivity detected in the spinal column, rib and epidermal tissue (Fig. 1c) might stem from 


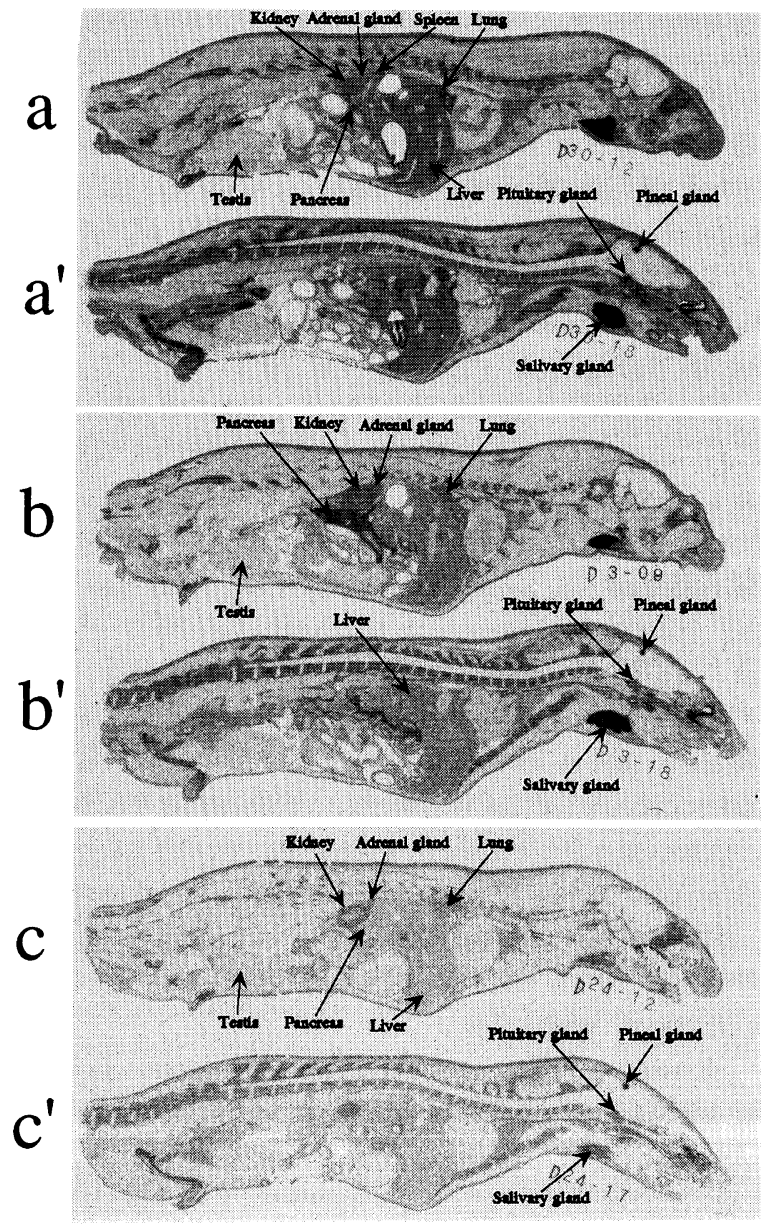

Fig. 1. Whole body autoradiograms of male rats (SpragueDawley, 7-week-old) at a time point of $0.5 \mathrm{hr}$ (a, a'), $3 \mathrm{hr}$ $\left(b, b^{\prime}\right)$ and $24 \mathrm{hr}\left(\mathrm{c}, \mathrm{c}^{\prime}\right)$ after intravenous administration of ${ }^{14} \mathrm{C}$-D-Asp.

the accumulated and metabolized products of ${ }^{14} \mathrm{C}$-D-Asp.

Within $3 \mathrm{hr}$ to $24 \mathrm{hr}$, the rates of elimination of radioactivities were great in most of the tissues except the pineal gland, pituitary gland, adrenal gland and testis (Table I), where the amounts of D-Asp in situ was high in rats. ${ }^{8), 9)}$

When rats (7-week-old) were administered with ${ }^{14} \mathrm{C}$ L-Asp, the autoradiograms obtained (Figs. 2a, b and c) showed the accumulation and elimination of the radioactivities to the same tissues as those with ${ }^{14} \mathrm{C}-\mathrm{D}$-Asp (Figs. 1a, $\mathrm{b}$ and $\mathrm{c}$ ). The quantification data (Table II) show that the tissue radioactivities at $0.5 \mathrm{hr}$ were very similar to those obtained in the case of ${ }^{14} \mathrm{C}$-D-Asp. However, the elimination of the radioactivity within $3 \mathrm{hr}$ to $24 \mathrm{hr}$ in the pineal gland and pituitary gland was more rapid than that in the case of ${ }^{14} \mathrm{C}$-D-Asp, whereas in the other tissues the elimination of the radioactivities were similar between the two cases.

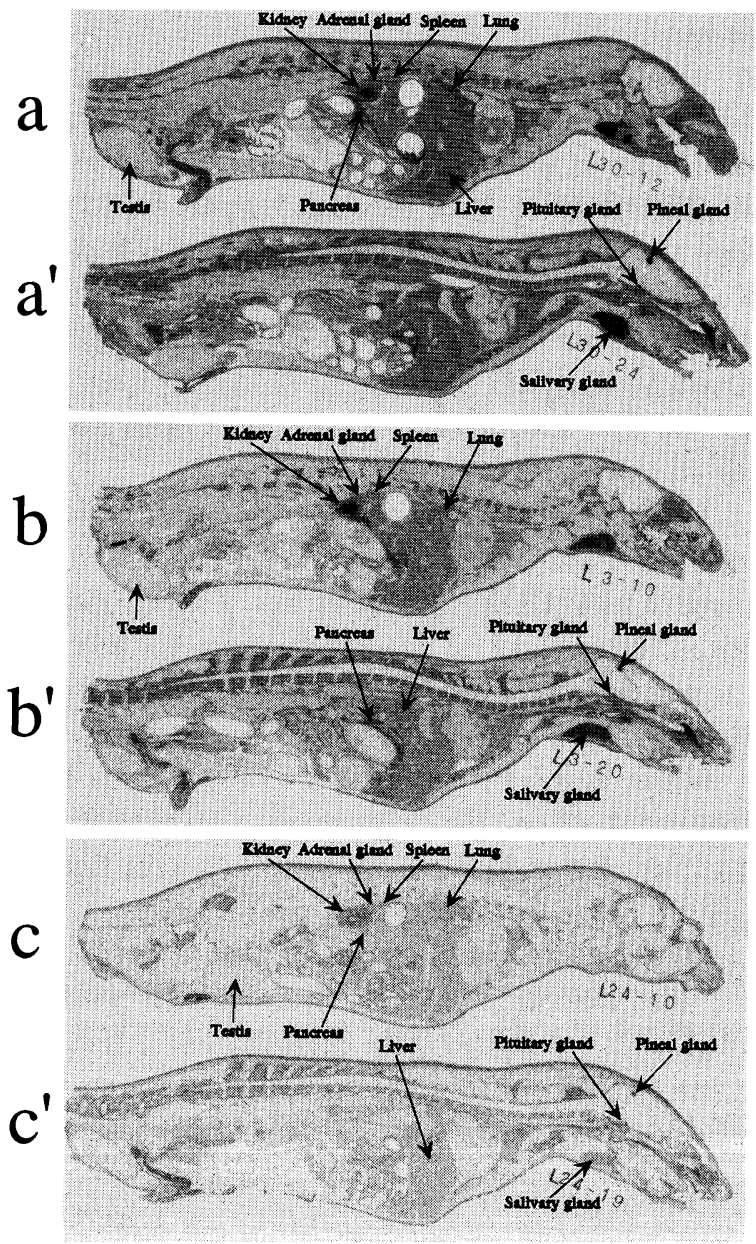

Fig. 2. Whole body autoradiograms of male rats (SpragueDawley, 7-week-old) at a time point of $0.5 \mathrm{hr}$ (a, a'), $3 \mathrm{hr}$ $\left(\mathrm{b}, \mathrm{b}^{\prime}\right)$ and $24 \mathrm{hr}\left(\mathrm{c}, \mathrm{c}^{\prime}\right)$ after intravenous administration of ${ }^{14} \mathrm{C}$-L-Asp.

Considering the above data that the distribution patterns of radioactivities of ${ }^{14} \mathrm{C}$-D-Asp into rat tissues were quite similar to those of tissues which were reported to contain D-Asp in situ, such as the pineal gland, ${ }^{9), 10)}$ pituitary gland, ${ }^{7 /-9)}$ liver, lung, adrenal gland, pancreas and spleen ${ }^{15)}$ except salivary gland for which there were no reports on the occurrence of D-Asp, we were intrigued by the presence of D-Asp in the salivary gland in situ. In the same way as reported in the previous paper, ${ }^{10)}$ the methanol extract from salivary gland (7-week-old rat) was derivatized with the fluorogenic reagent, NBD-F, and then subjected to HPLC separation, using two different stationary phases having the opposite chirality (Sumichiral OA-2500 (S) or -2500 (R)). The corresponding peaks to the standard NBD-D-Asp appeared on each of the chromatograms (the retention times, $51 \mathrm{~min}$ (Fig. 3a) and $49 \mathrm{~min}$ (Fig. 3b) for OA-2500 (S) and -2500 (R), 
Table I. Radioactivity in each rat tissue after intravenous administration of ${ }^{14} \mathrm{C}-\mathrm{D}$-Asp

\begin{tabular}{|c|c|c|c|c|c|}
\hline \multirow{2}{*}{ Tissues } & $0.5 \mathrm{hr}$ & $3 \mathrm{hr}$ & $24 \mathrm{hr}$ & \multicolumn{2}{|c|}{ ratio } \\
\hline & \multicolumn{3}{|c|}{$(\mathrm{dpm} / \mathrm{g})$} & $3 \mathrm{~h} / 0.5 \mathrm{~h}$ & $24 \mathrm{~h} / 3 \mathrm{~h}$ \\
\hline Blood & 4,749 & 4,570 & 1,659 & 0.962 & 0.363 \\
\hline Pineal gland & 289,011 & 75,221 & 53,841 & 0.260 & 0.716 \\
\hline Pituitary gland & 77,775 & 18,565 & 18,366 & 0.239 & 0.989 \\
\hline Salivary gland & 177,119 & 109,932 & 13,630 & 0.621 & 0.124 \\
\hline Liver & 22,107 & 12,084 & 4,697 & 0.547 & 0.389 \\
\hline Lung & 45,631 & 15,451 & 7,645 & 0.339 & 0.495 \\
\hline Adrenal gland & 18,892 & 15,349 & 8,967 & 0.812 & 0.584 \\
\hline Pancreas & 37,274 & 43,613 & 4,454 & 1.170 & 0.102 \\
\hline Testis & 4,611 & 3,635 & 2,276 & 0.788 & 0.626 \\
\hline Spleen & 21,561 & 15,398 & 6,575 & 0.714 & 0.427 \\
\hline
\end{tabular}

Table II. Radioactivity in each rat tissue after intravenous administration of ${ }^{14} \mathrm{C}$-L-Asp

\begin{tabular}{|c|c|c|c|c|c|}
\hline \multirow{2}{*}{ Tissues } & $0.5 \mathrm{hr}$ & $3 \mathrm{hr}$ & $24 \mathrm{hr}$ & \multicolumn{2}{|c|}{ ratio } \\
\hline & & $(\mathrm{dpm} / \mathrm{g})$ & & $3 \mathrm{~h} / 0.5 \mathrm{~h}$ & $24 \mathrm{~h} / 3 \mathrm{~h}$ \\
\hline Blood & 5,142 & 4,376 & 1,573 & 0.851 & 0.359 \\
\hline Pineal gland & 259,267 & 94,849 & 27,978 & 0.366 & 0.295 \\
\hline Pituitary gland & 109,217 & 44,316 & 16,736 & 0.406 & 0.378 \\
\hline Salivary gland & 124,894 & 51,661 & 7,802 & 0.414 & 0.151 \\
\hline Liver & 19,834 & 12,047 & 4,200 & 0.607 & 0.349 \\
\hline Lung & 34,473 & 9,604 & 5,281 & 0.279 & 0.550 \\
\hline Adrenal gland & 22,233 & 11,164 & 5,700 & 0.502 & 0.511 \\
\hline Pancreas & 43,567 & 30,050 & 3,171 & 0.690 & 0.106 \\
\hline Testis & 3,702 & 2,570 & 1,614 & 0.694 & 0.628 \\
\hline Spleen & 17,980 & 12,547 & 6,862 & 0.698 & 0.547 \\
\hline
\end{tabular}

respectively), indicating the presence of D-Asp in the salivary gland. Furthermore, the values of D-Asp obtained by the two HPLC separation were the same $(7.85 \pm 1.00$ $\mathrm{nmol} / \mathrm{g}$ tissue), assuring the purity of the peak and the accuracy of the values of D-Asp present in the salivary gland. Thus, it was clearly demonstrated for the first time that D-Asp is present in rat salivary gland in situ, although the concentration was low as compared with those in the pituitary gland, pineal gland and other peripheral tissues such as adrenal gland and testis. ${ }^{10), 14), 15)}$

Discussion. According to the previous reports, DAsp emerges in the early stages of development of mammalian tissues such as retina, brain and testis, and disappears at later stages. In rat cerebrum, $160 \mathrm{nmol} / \mathrm{g}$ of D-Asp at birth declines to $13 \mathrm{nmol} / \mathrm{g}$ at 10 days after birth. ${ }^{7)}$ In rat retina, the $\% \mathrm{D}$ changes from $10 \%$ to $29 \%$ after 7 days and becomes a few $\%$ after 15 days. ${ }^{4}$ In the rat pineal gland its concentration was high (1030 $\mathrm{pmol} /$ pineal gland) at the age of 6 weeks and decreased with aging. ${ }^{10)} \mathrm{A}$ similar emergence was also observed in rat
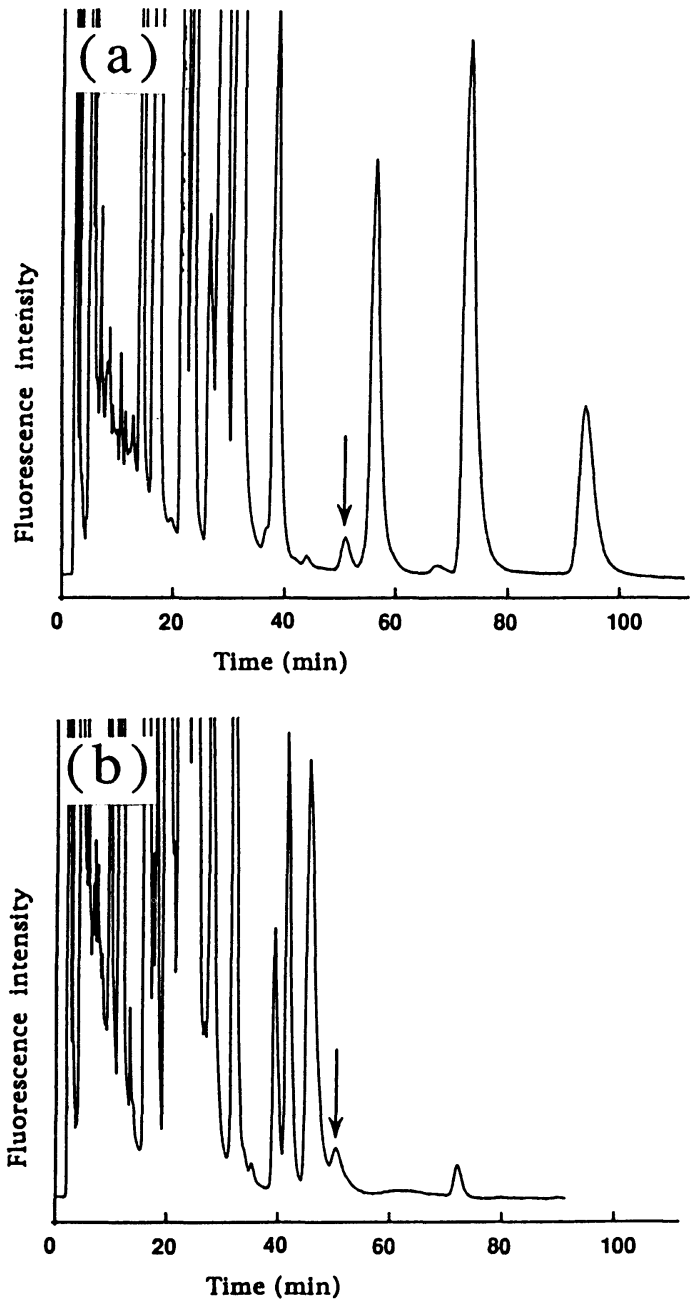

Fig. 3. Chromatograms of methanol extracts from salivary gland of male rats (Sprague-Dawley, 7-week-old) on Sumichiral OA-2500 (S)(a) and Sumichiral OA-2500 (R)(b). The arrow in the chromatogram indicates the peak of NBD-D-Asp. Mobile phase employed was $8.0 \mathrm{mM}$ citric acid in $\mathrm{MeOH}(\mathrm{a})$ and $10 \% \mathrm{CH}_{3} \mathrm{CN}$ in $8.0 \mathrm{mM}$ citric acid in $\mathrm{MeOH}(\mathrm{b})$. The other HPLC conditions are described in the text.

testis. ${ }^{11)}$ This kind of a transient and distinct peak period of emergence of D-Asp prompted the previous investigators to assume the in vivo synthesis of D-Asp in the mammalian body. ${ }^{11)}$ However, no supposed precursors such as phospho-L-Ser postulated for D-Ser have not yet been indicated. ${ }^{17)}$

The present results clearly indicate that D-Asp in the circulating blood distributes, accumulates and is deposited in the pineal gland, pituitary gland, and other peripheral tissues including salivary gland, since 1) the tissues where the radioactivity was distributed after the administration of ${ }^{14} \mathrm{C}$-D-Asp were the same as those which contained D-Asp in situ, except salivary gland, and 2) salivary gland was 
found to contain D-Asp in situ. The reason of low amount of D-Asp $(7.85 \pm 1.00 \mathrm{nmol} / \mathrm{g})$ as compared with the other tissues such as pineal gland $(3524 \mathrm{nmol} / \mathrm{g})^{9)}$ and pituitary gland $(80.5 \mathrm{nmol} / \mathrm{g})^{9)}$ was that the accumulated D-Asp from blood stream might be eliminated rapidly as judged from the rather rapid elimination of the radioactivity in the salivary gland. The tissues in which radioactivity decreased slowly, such as the pineal gland, pituitary gland, adrenal gland and testis, seem to contain a high concentration of DAsp owing to the slow rate of elimination.

One of the sources of the blood D-amino acids may be the daily intake from the diet since the foods and drinks contain D-amino acids, ${ }^{18), 19)}$ especially in fermented products such as cheese and wine. ${ }^{20), 21)}$ Vegetables and fruits also contain D-amino acids. ${ }^{22)} \mathrm{A}$ great amount of DAsp $(50 \pm 1 \mathrm{nmol} / \mathrm{g})$ was also found in the diet (CE-2) for rats. ${ }^{23)}$ These $\mathrm{D}$-amino acids have to be absorbed from the intestine at the same site as for L-amino acids ${ }^{24), 25)}$ and circulate into the blood stream. Certainly, Konno et al. demonstrated in mouse the absorption of the dietary DMet and its circulation in blood, since D-Met in urine disappeared when the animal was fed with the diet without D-Met. ${ }^{26)}$

In the present experiment, rats used were also fed with CE-2 which contain D-Asp, which probably was absorbed into rats, circulated in the blood stream, distributed into and accumulated in the specific tissues. It should be further clarified whether the dietary D-Asp or DAsp de novo synthesized is the true source of the tissue DAsp.

The next effort has to be focussed on the mechanism of transport of the circulating D-Asp into the specific tissues such as the pineal, pituitary and salivary glands. There might be some in situ transporter protein for D-Asp which has been an artificial marker for studying the tranport of L-Glu in the tissue cells. ${ }^{27)}$

In conclusion, the present study suggests the incorporation and deposit of D-Asp from the circulating blood into the specific tissues such as the pineal gland, pituitary gland, salivary gland, adrenal gland and testis. The results presented in this paper may stimulate further work on the origin, metabolism and biological roles of D-Asp in mammals.

Acknowledgements. The authors ackowledge support from the Ministry of Education and Science for the part of this work. Thanks are also due to Dr. C. K. Lim for his kind advice on the preparation of the manuscript.

\section{References}

1) Imai, K., Fukushima, T., Santa, T., Homma, H., Hamase, K.,
Sakai, K., and Kato, M. (1996) Biomed. Chromatogr. 10, 303-312.

2) Schell, M. J., Molliver, M. E., and Snyder, S. H. (1995) Proc. Natl. Acad. Sci. U.S.A. 92, 3948-3952.

3) Hashimoto, A., Nishikawa, T., Oka, T., and Takahashi, K. (1993) J. Neurochem. 60, 783-786.

4) Neidle, A., and Dunlop, D. S. (1990) Life Sci. 46, 1517-1522.

5) Hashimoto, A., Oka, T., and Nishikawa, T. (1995) Eur. J. Neurosci. 7, 1657-1663.

6) Hashimoto, A., Kumashiro, S., Nishikawa, T., Oka, T., Takahashi, K., Mito, T., Takashima, S., Doi, N., Mizutani, Y., Yamazaki, T., Kaneko, T., and Ootomo, E. (1993) J. Neurochem. 61, 348-351.

7) Dunlop, D. S., Neidle, A., McHale, D., Dunlop, D. M., and Lajtha, A. (1986) Biochem. Biophis. Res. Commun. 141, $27-32$.

8) Hashimoto, A., Nishikawa, T., Oka, T., Hayashi, T., and Takahashi, K. (1993) FEBS Lett. 331, 4-8.

9) Hamase, K., Homma, H., Takigawa, Y., Fukushima, T., Santa, T. and Imai, K. (1997) Biochim. Biophys. Acta (in press).

10) Imai, K., Fukushima, T., Hagiwara, K., and Santa, T. (1995) Biomed. Chromatogr. 9, 106-109.

11) D'Aniello, A., Cosmo, A.D., Cristo, C. D., Annunziato, L., Petrucelli, L., and Fisher, G. (1996) Life Sci. 59, 97-104.

12) Imai, K., and Watanabe, Y. (1981) Anal. Chim. Acta 130, 377-383.

13) Imai, K., Uzu, S., Kanda, S., and Baeyens, W. R. G. (1994) Anal. Chim. Acta 290, 3-20.

14) Imai, K., Fukushima, T., and Uzu, S. (1993) Biomed. Chromatogr. 7, 177-178.

15) Fukushima, T., Kato, M., Santa, T., and Imai, K. (1995) Biomed. Chromatogr. 9, 10-17.

16) D'Aniello, A., D’Onofrio, G., Pischetola, M., D'Aniello,G., Vetere, A., Petrucelli, L., and Fisher, G. H. (1993) J. Biol. Chem. 268, 26941-26949.

17) Wood, P. L, Hawkinson, J. E., and Goodnough, D. B. (1996) J. Neurochem. 67, 1485-1490.

18) Man, E. H., and Bada, J. L. (1987) Ann. Rev. Nutr. 7, 209-225.

19) Zagon, J., Dehne, L. I., and Bogl, K. W. (1994) Nutrition Res. 14, 445-463.

20) Bruckner, H., Langer, M., Lupke, M., Westhauser, T., and Godel, H. (1995) J. Chromatogr. A. 697, 229-245.

21) Kato, M., Fukushima, T., Santa, T., Homma, H., and Imai, K. (1995). Biomed. Chromatogr. 9, 193-194.

22) Bruckner, H., and Westhauser, T. (1994) Chromatographia. 39, 419-426.

23) Kera, Y., Aoyama, H., Matsumura, H., Hasegawa, A., Nagasaki, H., and Yamada, R. (1995) Biochim. Biophys. Acta 1243, 283-286.

24) Oxender, D. L. (1965) J. Biol. Chem. 240, 2976-2982.

25) Schultz, S. G., Yu-Tu, L., and Strecker, C. K. (1972) Biochim. Biophys. Acta 288, 367-379.

26) Konno, R., Isobe, K., Niwa, A., and Yasumura, Y. (1988) Metab. Clin. Exp. 37, 1139-1142.

27) Maenz, D. D., Chenu, C., Breton, S., and Berteloot, A. (1992) J. Biol. Chem. 267, 1510-1516. 